\title{
EFEKTIVITAS PEMBELAJARAN BAGI MURID DI MADRASAH IBTIDAIYAH
}

\author{
Millata Hanifa', Rusma Permana ${ }^{2}$, Miftahul Ulfah ${ }^{3}$ \\ STAI KH. Abdul Kabier ${ }^{1}$, STAI KH. Abdul Kabier ${ }^{2}$, STAI KH. Abdul Kabier ${ }^{3}$ \\ Email : millahanifa91@gmail.com, rusmermana@gmail.com², \\ ulfahmiftahul@yahoo.co.id ${ }^{3}$
}

\begin{abstract}
The existence of madrasah ibtidaiyah is equivalent to elementary school as part of basic education. The core activity of a school or madrasa is learning. Children enrolled by their parents in the madrasah ibtidaiyah are so that children can easily learn a number of important basic subjects so that children become pious children. In other words, children who learn will become adults, because they master a number of subjects, or the knowledge needed according to the curriculum to live in society, or continue to higher education. For this reason the effectiveness of learning becomes the teacher's task, because it requires professional teachers who are able to realize successful learning, especially seen from changes in student behavior, both cognitive, affective, and psychomotor.
\end{abstract}

Keywords : Effectiveness, Madrasah Ibtidaiyah, Learning.

Abstrak : Keberadaan madrasah ibtidaiyah setara dengan sekolah dasar sebagai bagian dari pendidikan dasar. Kegiatan inti sekolah atau madrasah adalah pembelajaran. Anak-anak yang didaftarkan orang tuanya ke madrasah ibtidaiyah adalah supaya anak dapat dengan mudah mempelajari sejumlah mata pelajaran dasar yang penting sehingga anak menjadi anak yang sholeh. Dengan kata lain anak yang belajar akan menjadi orang dewasa, karena mereka menguasai sejumlah mata pelajaran, atau pengetahuan yang diperlukan sesuai kurikulum untuk hidup di masyarakat, atau melanjutkan ke jenjang pendidikan lebih tinggi. Untuk itu efektivitas pembelajaran menjadi tugas guru, karena itu diperlukan guru profesional yang mampu mewujudkan pembelajaran yang berhasil, khususnya dilihat dari perubahan perilaku murid, baik kognitif, afektif, dan psikomotorik.

Kata Kunci : Efektivitas, Madrasah Ibtidaiyah, Pembelajaran. 


\section{PENDAHULUAN}

Peran strategis pendidikan nasional perlu terus ditingkatkan kualitasnya, baik pendidikan pra sekolah, pendidikan dasar, menengah dan pendidikan tinggi. Muara yang akan dicapai adalah pengembangan kualitas sumberdaya manusia (SDM) bangsa sebagai perencana, pemikir, dan pelaksana pembangunan nasional. Karena salah satu tujuan nasional Indonesia merdeka adalah mencerdaskan kehidupan bangsa. Untuk itu pelaksanaan pendidikan nasional harus bersifat sistemik, terencana dan berkelanjutan. Melalui pendidikan nasional, maka peran sosial, baik pegawai pemerintah, dokter, teknokrat, ahli hukum, pengacara, akuntan public, maupun guru dengan berbagai keterampilan, pengetahuan dan keahlian diperoleh dan dikuasai dari program pendidikan yang dilaksanakan oleh sekolah, pesantren dan madrasah. Peran guru dalam membelajarkan murid di madrasah Ibtidaiyah sangat strategis karena guru yang menentukan arah perkembangan anak, baik kemampuan membaca, menulis, menghitung (Calistung), selain pendidikan agama dan moral.

Kini manusia hidup dalam dunia yang penuh guncangan perubahan. Data baru, orang baru, ilmu dan teknologi baru dan lingkungan baru serta problem baru. Begitu pula manusia sedang mengalami penghancuran setiap hari dengan sesuatu yang baru. Pergantian realitas yang baru, lebih cepat dari kemampuan manusia dalam menangani perubahan baru. Dalam guncangan dunia, maka metode problem solving tradisional, tidak cukup efektif untuk semua situasi. Metode curah pikiran tradisional tidak cukup untuk mengatasi masalah.kita membutuhkan cara-cara baru dalam menangani masalahmasalahyang dihadapi. Maka solusi kreatif dapat dicarikan dengan latihan untuk mencapai hasil pemecahan masalah yang diharapkan. Kelompok membutuhkan keragaman kemampuan berpikir dalam memajukan gagasan ideal, menggerakkan pendekatan dan bagaimana menerapkan gagasan baru.

Keberadaan sekolah dasar merupakan periode penting, bahkan mungkin yang paling penting, dalam pembelajaran anak-anak. Pada masa ini anak-anak harus diajarkan keterampilan-keterampilan yang kompleks dan merupakan dasar dari semua pembelajaran yang mereka akan lakukan dalam kehidupannya. Dalam hal ini peran guru utama/guru kelas di sekolah dasar bahwa anak-anak diajarkan membaca, menulis, untuk memanipulasi angka, untuk mengamati dan merekam pengalaman mereka di dunia, dan menyediakan mereka dengan pengalaman yang merangsang imajinasi mereka dan memperluas dunia mereka. Sekarang ini guru $\mathrm{SD}$, jauh dari yang dilihat sebagai pengawal anak dengan keahlian yang sedikit, dipandang sebagai yang membolehkan dilakukannya belajar profesional, memiliki berbagai keterampilan sangat kompleks yang harus digunakan dalam kerjasama dengan visi dan imajinasi. ${ }^{1}$

Bahkan pada periode pendidikan ini, kebanyakan orang tua terlibat dalam pendidikan dasar (sekolah dasar) merupakan suatu yang tidak mudah sebagaimana halnya secara mekanis melihat proses pendidikan. Memasukkan anak ke sekolah; para murid diajarkan mata pelajaran- selanjutnya mereka mengikuti ujian, bahkan mereka kemudian memasuki gerbang selanjutnya/sekolah jenjang berikutnya. Biasanya para orang tua sudah merasa senang begitu anaknya diterima masuk sekolah sesuai yang diinginkan, dan para guru bisa mengajar anak-anak dengan baik, menyediakan anak-anak dengan mata

1 James Arthur, Teresa Grainger and David Wray, Learning to Teach in The Primary School, (London: Rouyladge, 2006), h.1. 
pelajaran dan peluang cepat menyelesaikan kurikulum formal sesuai ketentuan pemerintah.

Sejatinya, kegiatan inti sekolah adalah pembelajaran. Seluruh komponen sekolah, baik manajemen, kepemimpinan, sumberdaya manusia (pendidik dan tenaga kependidikan, kurikulum, sarana prasarana, media dan iklim) menjadi faktor yang dimanfaatkan oleh manajer dan pemimpin untuk mendukung terlaksananya pembelajaran. Sejalan dengan itu, pembelajaran pada dasarnya kegiatan terencana yang mengondisikan atau merangsang seseorang agar hasil belajar dengan baik dan sesuai dengan tujuan pembelajaran. ${ }^{2}$ Pelaksanaan pembelajaran dapat berlangsung di dalam kelas dan di luar kelas menjadi tanggung jawab guru. Setiap sekolah memerlukan tersedianya guru profesional yang mahir merencanakan, mengatur sumberdaya, melaksanakan kurikulum, dan mengevaluasi pembelajaran.

Untuk itu, perlu keterampilan komunikasi para guru dalam melaklsanakan pembelajaran. Dalam menyelenggarakan pembelajaran yang bermutu, komunikasi dan interaksi yang dilakukan guru perlu dilandasi dengan kemampuan akademik peserta didik, penyesuaian adptasi sosial peserta didik, peranan orang tua dan sumber primer pendidikan lainnya untuk membantu peserta didik mencapai keberhasilan dalam pendidikan. ${ }^{3}$ Selain itu pengembangan kurikulum memiliki peranan penting dalam keberhasilan anak. Pengembangan kurikulum berjalan dengan baik ketika kebijakan kurikulum mendukung kurikulum. ${ }^{4}$ Kurikulum menentukan arah atau condong kemana peserta didik dan keoptimalan dalam tujuan pendidikan. ${ }^{5}$

Hampir setiap survey dilakukan berkenaan motivasi guru sekolah dasar disimpulkan bahwa mereka tidak hanya ingin murid mereka melakukan secara akademik baik, tetapi juga memiliki kematangan sosial, emosional, dan secara spiritual. Keinginan ini merupakan refleksi dalam cara berbicara guru dengan anak-anak murid daripada sesame muridnya. ${ }^{6}$ Menjadi seorang guru senyatanya menjadi pandangan hidup, sebagaimana halnya guru professional lebih menjadi seorang guru yang tidak sekedar menyampaikan mata pelajaran.

Disinilah pentingnya kemampuan guru dalam komunikasi. Dalam konteks ini ditegaskan bahwa "Teachers with effective communication skill have more positive working relationships not only with their students, but also with parents, administrators, supervisors, resource personnel and the community at large. More importantly, their highly effective communication skill help them resolve complex problems and avoid long-term difficulties that teachers with weaker communications skill often to overcome."7 Keterampilan komunikasi menjadi

2 Syafaruddin, Manajemen dan Strategi Pembelajaran, (Medan: Perdana Publishing, 2019),

h.178.

${ }^{3}$ Syafaruddin, Manajemen, h. 178.

${ }^{4}$ Mesiono, dkk., "Implementasi Kebijakan Pengembangan Kurikulum Madrasah Aliyah Qismul 'Aly Medan" dalam TA'DIB, Volume 22 Nomor 2, Desember 2019, h. 60.

${ }^{5}$ Mursal Aziz, dkk., Al-Washliyah Educational Council Policy in The Development of Madrasah Aliyah Curriculum in North Sumatera" dalam Abjadia : International Journal of Education, Volume IV, No. 1 Juni 2019, h. 33.

${ }^{6}$ Denis Hayes, ed, Joyful Teaching, and Learning in the Primary School, (London: Learning Matters, Ltd, 2007), h. 1

${ }^{7}$ Y Vonne Bender, The Tacthful Teacher:Communication With Parents, Colleagues and Administrators, (USA: Nomad Press, 2005), h.2. 
syarat efektivitas pembelajaran di tingkat dasar terutama pada jenjang SD/MI maupun SMP/MTs.

Potensi pendidikan dasar di Indonesia sangat determinan dalam memperepat pencerdaskan kehidupan bangsa. Jika pemerataan pendidikan dasardpat sudah tuntas sejak dari tahun 2000-an maka sudah saatnya fokus pada wajib belajar 12 tahun untuk jenjang pendidikan menengah SMA/MA/SMK. Oleh sebab itu, perlu dikaji seberapa besar kontribusi komunikasi efektif guru dalam pembelajaran di Madrasah Ibtidaiyah? Kajian teoretis ini berusaha menjelaskan mengenai efekjtivitas pembelajaran bagi murid di Madrasah Ibtidaiyah.

\section{METODOLOGI PENELITIAN}

Penelitian ini merupakan kajian literatur yang disusun secara sistematis tentang efektivitas pembelajaran bagi murid di MI. Jenis penelitian yang digunakan dalam penelitian ini adalah penelitian kualitatif dengan metode studi kepustakaan. Untuk itu, pengecekan data riset menggunakan bahan literatur.

\section{HASIL DAN PEMBAHASAN}

Guru dan Pembelajaran Guru merupakan salah satu komponen pembelajaran, selain siswa/anak didik, kurikulum, media, strategi, tujuan pembelajaran, manajemen, dan kepemimpinan, sarana dan prasarana. Guru mengajar peserta didik dengan perencanaan, program kurikulum, tujuan, metode dan strategi lalu berinteraksi dengan anak didik, maka terciptalah iklim pembelajaran. Konteks kegiatan pembelajarannya dapat berlangsung di SD/MI, SMP/MTs/MA dan SMK. Konteks pembelajaran yang tercipta di pendidikan dasar (SD/MI) dan SMA/MA/SMK akan berbeda disebabkan keragaman usia dan lalar belakang anak didik tentu saja berbeda. Dialektika anak didik, guru dan konteks pembelajaran, ${ }^{8}$

Digambarkan sebagai berikut:

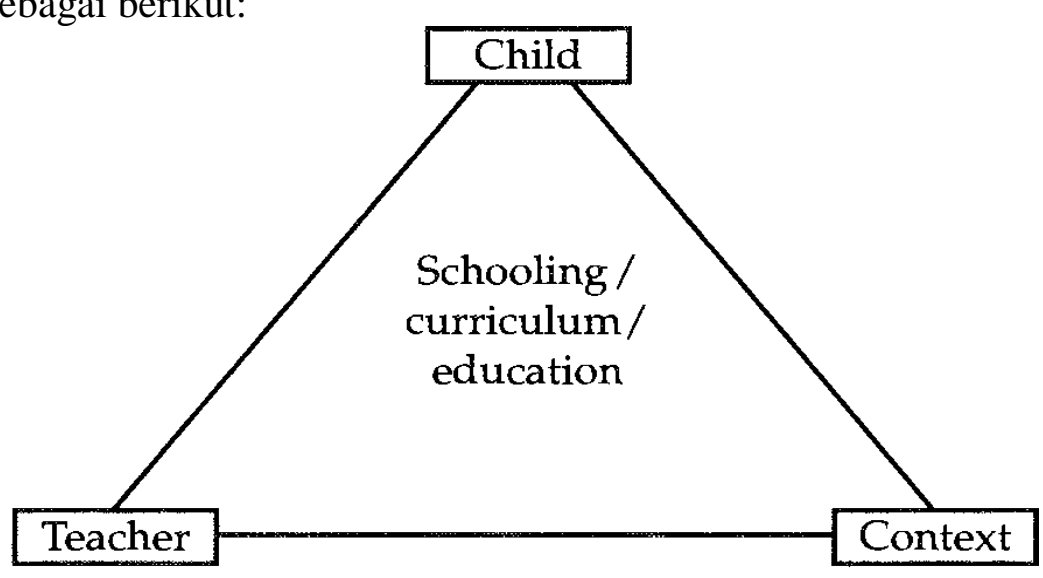

Figure 1 Child, teacher, context

Salah satu permasalahan yang dihadapi guru dalam keseharian tugas pembelajaran di sekolah adalah sukarnya mengatur anak untuk disiplin mengikuti pembelajaran. Kalau di dalam kelas pada dasawarsa 60-an dan 70-an, anak-anak ketika belajar di dalam kelas sangat teratur, dengan melipat tangan, duduknya rapi menghadap ke depan semuanya mengarah kepada guru di depan papan tulis.

${ }^{8}$ Florence Beetlestone, Creative Children, Imaginative Teaching, (Buckingham: Open University Pres, 1998), h. xii. 
Ketika itu, memang sumber pengetahuan utama muridmurid adalah guru yang mengajar di depan kelas. Namun, dalam perkembangan kontemporer, nampaknya zaman berubah begitu cepat.

Kepatuhan anak dalam mengikuti perintah guru semakin sukar mendapatkannya. Anak-anak memiliki bekal nilai-nilai yang banyak dari lingkungannya. Bahkan, banyak masalah-masalah yang dibawanya ke kelas dari lingkungannya di rumah dan di masyarakat. Sehingga banyak pertanyaanpertanyaan dan keluhan anak begitu masuk ke dalam kelas ketika pembelajaran akan dimulai oleh guru. Keadaan yang demikian juga dihadapi oleh guru dalam pembelajaran mata pelajaran pendidikan agama Islam. Dari berbagai dampak kurangnya perhatian orang tua terhadap kebutuhan anak, siaran televisi yang kurang mendidik, pengaruh lingkungan sosial dan pergaulan yang jelek terhadap anak, meluasnya layanan game yang mengandung konten kekerasan, dan internet yang bernuansa seks menjadi makanan tambahan dalam keseharian anak jika anak-anak tidak diawasi.

Begitu anak memasuki kelas, seakan dirasanya terpenjarakan sehingga memunculkan sikap kurang menyenangkan ketika setiap guru melakukan pengelolaan kelas dengan mulai mengatur anak. Fenomena menunjukkan bahwa anak-anak tidak mau diatur untuk rapi dan tentram, semua mau berbicara, sejak dari persoalannya di rumah, dengan kawannya, dan masalahmasalah di luar kelas dibawanya serta ke sekolah. Oleh sebab itu, diperlukan pemahaman menyeluruh tentang perbedaan anak-anak lalu dikomunikasikan untuk mengatur dirinya sendiri mengikuti pembelajaran yang akan disampaikan oleh guru. Bagaimanapun, efektivitas pengajaran memang diperlukan. Para guru harus memahami bahwa anak-anak memiliki sejarah dan pengalaman pribadi yang kadang-kadang mempengaruhinya.

Dalam kenyataan, bahwa anak-anak tersebut tidak dapat meninggalkan secara sederhana tentang problemanya di luar sekolah ketika dia memasuki kelas pada pagi hari dan hari demi hari sampai berakhir. Permasalahan siswa akan dibawanya bersama ke dalam kelas yang dikelola guru. Keterampilan untuk mengelola siswa dan semua jenis siswa dengan semua masalahnya menjadi hal esensial kepada lebih banyak guru yang ingin semakin efektif. ${ }^{9}$ Komunikasi Dalam Pembelajaran Proses pembelajaran melibatkan persiapan dan perencanaan untuk belajar anak, pengorganisasian kelas, pengaturan sumber-sumber pengajaran, pengelolaan kunjungan atau kegiatan di luar kelas dan pengarahan dari orang dewasa lainnya yang bekerja mengembangkan pribadi anak-anak. Karena itu tugas guru dalam mengelola pengajaran sebenarnya merencanakan, mempersiapkan dan mengatur pekerjaan mereka membelajarkan anak untuk mencapai tujuan pembelajaran. Guru benar-benar terlibat dalam mengajar sebagai proses menjalankan karirnya. Begitu pula, mengajar sebagai kegiatan professional, meniscayakan guru terlibat dalam berbagai kegiatan ekstra kelastugas administrasi, rapat staf, klub, konsultasi dengan orang tua dan kehadiran dalam latihan pengembangan profesional. ${ }^{10}$

Definisi yang luas dapat membuat pembelajaran lebih bermakna dan dapat menyenangkan, sehingga pengajaran lebih merangsang dan menimbilkan

${ }^{9}$ Robert T. Tauber, Classroom Management: Sound Theory and Effective Practice, (London: Praeger, 2007), h. 17.

${ }^{10}$ Burton, Meil and Mrk Brundrett, Leading the Curriculum in The Primary School, (London: Paul Chapman Publishing, 2005), h. 15. 
imajinasi dan kurikulum lebih luas dan lebih menakjubkan. Adakah semua anakanak dn guru memiliki potensi untuk menjadi kreatif? Dapatkan penghitungan dasar dan keterampilan literasi secara lebih siap merupakan kerjasama ke dalam kegiatan kreatif? Di sini berpikir kreatif dan pemecahan masalah merupakan jaringan hubungan keduanya. ${ }^{11}$

Guru dengan keterampilan komunikasi yang efektif memiliki hubungan kerja yang lebih positif tidak hanya dengan siswa mereka, tetapi juga dengan orang tua, administrator, pengawas, personel sumber daya dan masyarakat pada umumnya. Lebih penting lagi, keterampilan komunikasi mereka yang sangat efektif membantu mereka menyelesaikan masalah yang rumit dan menghindari kesulitan jangka panjang yang seringkali harus diatasi oleh guru dengan keterampilan komunikasi yang lebih lemah. ${ }^{12}$ Cara untuk mencegah kesalahpahaman tersebut adalah dengan memahami dan menerapkan strategi komunikasi yang efektif. ${ }^{13}$ Ada sepuluh strategi untuk membangun komunikasi yang efektif.

Berikut ini adalah beberapa strategi yang dapat Anda gunakan untuk membuat keterampilan komunikasi Anda lebih efektif; (1) Sesuaikan komunikasi Anda agar sesuai dengan situasinya, (2) Ketahui dan ikuti rantai komando komunikasi sekolah Anda, (3) Buka jalur komunikasi sebelum masalah mulai dan bekerjalah agar tetap terbuka, (4) Mulailah secara positif, (5) Berlatih mendengarkan aktif, (6) Tekankan bidang perjanjian, (7) Bersedia kompromi, (8) Hormati kerahasiaan, (9) Hindari gosip, (10), Akhiri dengan nada positif. ${ }^{14}$

Kesepuluh strategi tersebut perlu diaplikasikan oleh guru dalam membelajarkan anak. Sebab usia anak sekolah dasar atau pada Madrasah Ibtidaiyah meman usia dasar, karena itu komunikasi membelajarkan anak harus menggunakan bahasa anak dan penuh persuasive, motivatif, dan menyenankan hati. Jika kata-kata yang digunakan jelas, tegas, menyejukkan, dan menyenangkan maka anak merasa dilindungi dengan pembelajaran yang disampaikan guru, tentu saja sesuai dengan tujuan, atau kompetensi yang akan dicapai sebagaimana dalam rencana pelaksanaan pembelajaran. Perlu ditegaskan bahwa perilaku manajemen bukan menjadi tujuan dan proses kegiatannya. Hal ini merupakan cara menjamin bahwa pekerjaan dilakukan secara efektif. Guncangan masalah para pelajar lebih sering menapaikemenangan dari pada terkendali, atau fokus pada pekerjaan, daripada perilaku, memberikan kemahiran dalam menangkap peluang. Sebagai seorang guru sesungguhnya memilikimkekuataan untuk mengubah apa yang terjadi.

Guru di sekolah dasar, ${ }^{16}$ keberadaan guru di sekolah dasar selalu mengharapkan murid yang penuh kebaikan atau yang baik. Para murid menghabiskan waktu kesehariannya dengan terbaiknya dengan para guru, dan memiliki peluang untuk mempengaruhi murid. Waktu dihabiskan oleh murid dalam kerjasama dengan guru karena itu interaksi nya sangat bermakna. Guru yang baik berhubungan dengan muridnya mereka di dalam hatinya dalam praktik

\footnotetext{
${ }^{11}$ Beetlonce, Creative, h. xiv

${ }^{12}$ YVonne Bender, The Tachful Teacher:Communication With Parents, Colleagues and Administrators, (USA: Nomad Press, 2005), h. 2.

${ }^{13}$ Ibid., h..4.

${ }^{14}$ Ibid., h.5.

15 ibid

${ }^{16}$ James Arthur, Teresa Grainger and David Wray, Learning to Teach in The Primary School, (London: Rouyladge, 2006), 2.
} 
pendidikan adalah hubungan antara guru dengan murid yang tertata sebagaimana disuarakan di dalam kelas. Untuk semua alasan ini ketika membicarakan pembelajaran menggunakan jika professional yang diputuskan untuk menghadirkan. Jadi cara ketiga konseptualisasi pengajaran di sekolah dasar dan pendekatan dalam kajian ini. ${ }^{17}$

Guru utama adalah guru mengajar di Ibtidaiyah atau sekolah dasar, sebab mereka mengajarkan semua pengetahuan, kecuali mata pelajaran olah raga, pendidikan agama, dan kesenian. Mata pelajaran ini diajarkan oleh guru kelas. Karena itu guru profesional, harus menguasai sejumlah karakteristik sebagai guru, yang mencakup;

1. Pengetahuan tingkat tinggi yang relevan tentang apa yang diajarkan dan murid kepada siapa itu diajar;

2. Pengetahuan, dan keterampilan dalam menggunakan, serangkaian strategi untuk mempresentasikan, menjelaskan dan mengilustrasikan ide-ide kepada peserta didik;

3. Kapasitas untuk terlibat dalam tindakan yang dipertimbangkan dan dipertimbangkan dalam menerapkan strategi semacam itu, dengan mempertimbangkan kebutuhan dan tanggapan peserta didik ketika mereka mengembangkan dan memanifestasikan diri;

4. Pemahaman tentang pentingnya sikap peserta didik terhadap apa yang mereka pelajari dan kemampuan untuk mempengaruhi dan mengembangkan sikap ini; dan

5. Kemampuan dan kemauan untuk belajar dari berbagai sumber tentang pengajaran yang efektif dan untuk menyesuaikan praktik agar sesuai dengan pembelajaran yang sedang berlangsung ini.

Berikut ini adalah temuan yang dibuat oleh berbagai peneliti tentang karakteristik guru yang efektif, yaitu:

1. Guru yang efektif mempersiapkan diri dengan baik dan memiliki tujuan yang jelas untuk mengajar murid;

2. Mereka bertujuan untuk membuat sebanyak mungkin kontak mengajar dengan semua murid;

3. Mereka bertujuan untuk melihat bahwa anak-anak menghabiskan waktunya sebanyak mungkin yang menguntungkan pada tugas;

4. Mereka memiliki harapan yang tinggi untuk berprestasi semua anak;

5. Mereka membuat presentasi yang jelas sesuai dengan tingkat kemampuan anak-anak;

6. Mereka membuat struktur bekerja dengan baik dan memberitahu anak-anak bahwa tujuan dan target pekerjaan yang mereka lakukan berharap anak-anak akan mencapainya;

7. Mereka bersikap fleksibel dalam berbagai perilaku dan kegiatan mengajar;

8. Mereka menggunakan banyak pertanyaan yang lebih tinggi untuk pengembangan kemampuan berpikir pada anak-anak;

9. Mereka memberikan umpan balik yang sering untuk anak-anak tentang bagaimana mereka lakukan sesuatu;

10. Mereka membuat penggunaan pujian yang tepat untuk prestasi dan perilaku;

${ }^{17}$ Bob Barnes, Primary Classroom Management, (London: Chapman Publishing, 2006), h. 27. 
11. Mereka menyimpan catatan yang baik dari pencapaian dan kemajuan masing-masing anak untuk digunakan, bersamaan kemajuan belajar terus dikaji;

12. Kelas mereka terorganisir dengan baik, memerintahkan anak dengan cara menarik;

13. Mereka merefleksikan pekerjaan siswa yang telah melakukan dan mengevaluasi kemajuan untuk mencapai tujuan. ${ }^{18}$

Jika 13 karakteristik guru efektif ini dapat diwujudkan maka pembelajaran efektif tidak sekedar konsep semata, tetapi dapat pula dicapai guru pada sekolah dasar, sebab guru di madrasah ibtidaiyah juga disebut sebagai guru utama, karena pengetahuan dasarnya yang mumpuni. Oleh sebab itu, agar pembelajaran efektif dapat dilaksanakan, maka pembelajaran efektif di sekolah dasar harus dimulai dari upaya komunikasi yang baik oleh guru kelas dengan siswa. Komunikasi dalam Pembelajaran Otonomi guru kelas di madrasah ibtidaiyah sangat kuat, maka faktor kepemimpinan guru di kelas menjadi penentu ketika mengambil keputusan. Kepemimpinan guru secara konsisten mengidentifikasi keterlibatan dalam pengambilan keputusan sebagai indikator kunci dari kekuatan kepemimpinan guru (Muijs dan Harris 2003) meskipun demikian, kepemipinan ini didukung keterampilan komunikasi.

Dalam konteks ini, dijelaskan bahwa: "The way to prevent such misunderstanding is to understand and implement effective communication strategies". ${ }^{19}$ Ada sepuluh strategi untuk membangun komunikasi yang efektif. Berikut ini adalah beberapa strategi yang dapat Anda gunakan untuk membuat keterampilan komunikasi Anda lebih efektif; (1) Sesuaikan komunikasi Anda agar sesuai dengan situasi; (2) Ketahui dan ikuti rantai komando komunikasi sekolah Anda; (3) Buka jalur komunikasi sebelum masalah mulai dan bekerja untuk menjaga mereka tetap terbuka; (4) Mulai dengan positif; (5) Berlatih mendengarkan aktif; (6) Tekankan bidang kesepakatan; (7) Bersedia berkompromi; (8) Hormati kerahasiaan; (9) Hindari gosip; dan (10) Akhiri dengan nada positif. ${ }^{20}$

Pembelajaran efektif adalah pembelajaran yang menyenangkan bagi murid. Adapun pembelajaran menyenangkan tidak terjadi tanpa peluang. Pembelajaran tersebut dimungkinkan ketika murid dan guru melaksanakannya secara antusias dengan pembelajaran, tantangan bagus dan menjaga keberhasilan. Paling tidak ada empat hal yang menjadi strategi mencapai pembelajaran menyenangkan bagi guru, yaitu:

1. Bertekun untuk tetap positif. Bagi guru yang dilatih, musuh terbesar adalah ketakutan akan kegagalan, terlepas dari kenyataan itu sebagian besar peserta pelatihan tentang penempatan berhasil. Setiap pengalaman mengajar memiliki bagiannya masing-masing dan surut; pengalaman-pengalaman ini menunjukkan bahwa pembelajaran profesional sedang berlangsung dan tidak seharusnya terjadi dipandang sebagai indikator ketidakcukupan Anda.

2. Lihat mengajar sebagai petualangan. Renungkan kekuatan dan kelemahan Anda tetapi hindari merenung kekurangan. Mengajar adalah pekerjaan yang mendebarkan, tetapi seperti pekerjaan rumit lainnya, butuh waktu untuk

18 Joan Dean, Improving Children's Learning: Effective teaching in the

Primary School, (London: Routledge 2000), h. 3.

${ }^{19}$ Ibid., h. 4.

${ }^{20}$ Ibid., h. 5. 
berkembang dan dewasa. Perlakukan kemunduran sebagai slip-up yang akan mengarahkan Anda ke depan daripada ke bawah! Latih diri Anda untuk tersenyum pada kesalahan kecil dan bertindak untuk memperbaikinya alih-alih merenunginya dengan sedih. ${ }^{21}$

Kemampuan Verbal Guru membuat koneksi dengan siswa mereka, kolega, dan keluarga siswa melalui kata-kata dan tindakan. Guru yang efektif tahu siswa mereka dan bagaimana berkomunikasi dengan mereka, baik secara individu maupun kolektif. Beberapa siswa lebih memilih "hanya fakta-fakta" sementara yang lain ingin mendengar narasi, dan kemudian ada orang lain dengan gaya belajar yang sama sekali berbeda dan kebutuhan komunikasi. guru yang efektif hati-hati mempertimbangkan audiens mereka saat menyampaikan pesan. Mereka mengamati reaksi dan memutuskan cara terbaik untuk mendapatkan titik mereka menyeberang ke individu yang berbeda. $^{22}$

Hubungan antara efektivitas guru dan kemampuan verbal tidak baru (Hanushek, 1971). Memang, temuan ini hanya memverifikasi apa yang orang sudah tahu: kemampuan guru untuk berkomunikasi secara efektif pengaruh hubungan mereka membangun dengan orang lain, kejelasan penjelasan untuk stu-penyok, dan, selalu, pemahaman siswa dan prestasi. Sementara pejantanies mengenai hubungan antara kemampuan verbal dan efektivitas guru.

\section{KESIMPULAN}

Anak yang belajar akan menjadi orang dewasa, karena mereka menguasai sejumlah mata pelajaran, atau pengetahuan yang diperlukan sesuai kurikulum untuk hidup di masyarakat, atau melanjutkan ke jenjang pendidikan lebih tinggi. Untuk itu efektivitas pembelajaran menjadi tugas guru, karena itu diperlukan guru profesional yang mampu mewujudkan pembelajaran yang berhasil, khususnya dilihat dari perubahan perilaku murid, baik kognitif, afektif, dan psikomotorik. Hal ini akan dapat dikuasai anak bila memperoleh pengajaran yang tepat melalui cara berkomunikasi guru. Sebab, guru adalah pemimpin dalam proses pembelajaran.

\section{DAFTAR PUSTAKA}

Arthur, James, et.al., Learning to Teach in The Primary School. London: Routledge. 2006. Barnes, Bob. Primary Classroom Management. London: Chapman Publishing 2006.

Beetlestone, Florence. Creative Children, Imaginative Teaching, Buckingham: Open University Press, 1998.

Bender, Yvonne. The Tacthful Teacher: Communication With Parents, Colleagues and

Administrators, USA: Nomad Press Burton, Meil and Mrk Brundrett. Handbook for Qualities of Effective Teachers. Virginia: ASCD, 2004.

Burton, Meil and Mrk Brundrett. Leading the Curriculum in the Primary School. London: Paul Chapman Publishing 2005.

Dean, Joan. Improving Children's Learning: Effective teaching in the Primary School. London: Routledge, 2000.

\footnotetext{
${ }^{21}$ Joyful, Teaching and Learning, h. 7.

${ }^{22}$ Handbook for Qualities of Effective Teachers (Virginia: ASCD, 2004), h. 9.
} 
Hayes, Denis, (ed). Joyful Teaching, and Learning in the Primary School. London: Learning Matters, Ltd, 2007.

Mesiono, dkk., "Implementasi Kebijakan Pengembangan Kurikulum Madrasah Aliyah Qismul'Aly Medan" dalam TA’DIB, Volume 22 Nomor 2, Desember 2019.

Mursal Aziz, dkk., Al-Washliyah Educational Council Policy in The Development of Madrasah

Aliyah Curriculum in North Sumatera" dalam Abjadia : International Journal of Education, Volume IV, No. 1, 2019.

Syafaruddin. Manajemen dan Strategi Pembelajaran. Medan: Perdana Publishing, 2019.

Tauber, Robert T. Classroom Management: Sound Theory and Effective Practice. London: Praeger, 2007. 